\title{
Welfare effects of downstream mergers and upstream market
}

\section{concentration *}

\author{
Ramon Fauli-Oller ${ }^{\dagger}$ and Joel Sandonis ${ }^{\ddagger}$
}

July 2013

\begin{abstract}
We consider a dominant upstream firm selling an input to several downstream firms through observable, non-discriminatory two-part tariff contracts. Downstream firms can alternatively buy the input from a less efficient source of supply. In this setting we analyze the relationship between the competitive effects of downstream mergers and the level of concentration at the upstream level. We show that a downstream merger leads to lower wholesale prices. This translates into lower final prices only when the upstream market is sufficiently concentrated. In this case, a downstream merger tends to be both procompetitive and profitable.
\end{abstract}

Key words: downstream mergers, wholesale prices, two-part tariff contracts JEL codes: L11, L13 and L14.

${ }^{*}$ Financial support from Ministerio de Ciencia e Innovación and FEDER funds under project SEJ 2007-62656, from Spanish Ministerio de Economía y Competitividad under project ECO2012-34928 and the IVIE is gratefully acknowledged.

${ }^{\dagger}$ University of Alicante. Economics Department, Campus de Sant Vicent del Raspeig, E-03071, Alicante, Spain. E-mail address: fauli@ua.es.

${ }^{\ddagger}$ Corresponding author. University of Alicante. Economics Department, Campus de Sant Vicent del Raspeig, E-03071, Alicante, Spain. E-mail address: sandonis@ua.es. 


\section{Introduction}

In the last few years, we have observed the rise of very large downstream firms in previously more fragmented industries such as retailing, farming, natural resource extraction or health. This trend has raised antitrust concerns about their negative possible impact on prices and welfare. Even though the empirical literature that study the consequences of downstream mergers is scarce, the existing papers agree that their effects crucially depend on the suppliers' market concentration. For example, in Bhattacharyya and Nain (2011, p. 97) we can read: "consistent with the theory of countervailing power, concentrated suppliers and those with greater barriers to entry experience large price declines after downstream consolidation". In Fee and Tomas (2004, p. 450) we find: "Suppliers in concentrated industries experience significant reductions in cash-flows subsequent to the downstream mergers". They explain the key role played by supplier's concentration stating (p. 451) that when it is high is "when there are greater initial supplier rents for the (downstream) merging firms to capture".

In this paper we want to formally analyse the relationship between the competitive effects of downstream mergers and the level of competition in the upstream level. In order to address this issue, we consider a model with a dominant upstream firm selling an input to several downstream firms. They are engaged in Cournot competition in a homogenous good final market. The upstream firm offers observable, non-discriminatory two-part tariff contracts to sell the input to downstream firms. Downstream firms can alternatively obtain the input from a less efficient, competitive source of supply at cost c. So this alternative supply provides these firms with an outside option. If they reject the contract offered by the dominant upstream firm they can still be supplied at a higher cost by this alternative source of supply. Of course, this outside option is smaller the more inefficient the alternative supplier is (the higher is c). Parameter $\mathrm{c}$ in fact plays 
a key role in the paper and it allows us to relate the results we obtain with the empirical evidence presented above. It can be interpreted as an inverse measure of the degree of competition in the upstream sector. The reason is that, by increasing the value of c, we can move from the case of perfect competition upstream (this would be the case if the alternative supplier is as efficient as the dominant supplier) to the case of a monopolistic upstream sector (this would be the case when $\mathrm{c}$ is so large that the outside option of downstream firms becomes zero and then, as we will see, the upstream dominant firm monopolizes the market). In empirical studies, concentration is used as a proxy for the level of competition. Therefore, we can relate our results in c with the empirical evidence presented above. In particular, an increase in c in our paper corresponds to an increase in suppliers' concentration in the empirical studies.

In this setting, we show that the size of parameter $\mathrm{c}$ is key to determine the effects of downstream mergers on upstream profits, on prices and on social welfare. In particular, we show that:

(i) A downstream merger leads the upstream dominant firm to reduce the wholesale price. And more important for our welfare results, this reduction is higher the higher the value of parameter c (the more concentrated the upstream industry).

(ii) Downstream consolidation reduces upstream profits when c is high.

(iii) Profitability of downstream mergers is increasing in c.

(iv) For large enough values of c, a downstream merger turns out to be welfare improving.

Observe that points (i), (ii) and (iii) support the empirical observations presented above.

Concerning (i), downstream mergers reduce the wholesale price because the dominant upstream firm optimally chooses the wholesale price to balance two opposing incentives: an incentive to increase the size of the "total pie" (total industry profits) and an incentive to increase the fraction of a "lower pie" it gets (by reducing the outside option of downstream firms). The 
former calls for a high wholesale price. The latter one requires a low wholesale price. The optimal wholesale price trades-off these two opposing effects. A downstream merger affects the two previous incentives; on the one hand, by reducing the level of competition in the downstream market, it supports the first incentive. On the other hand, it also increases the outside option of downstream firms, hurting the second incentive. Then, a downstream merger makes the first incentive "less binding", leading the upstream firm to put more weight on the second one, reducing the wholesale price in order to reduce the outside option of downstream firms.

Key for our results is that this reduction in the wholesale price is larger the higher the value of c (except when $\mathrm{c}$ is so large that the upstream firm gets the monopoly profits and then the optimal wholesale price does not depend on c). A higher value of c reduces the outside option of downstream firms for a given number of them. This implies that a downstream merger produces a proportionally larger increase of the outside option that must be compensated by the upstream firm with a larger reduction of the wholesale price. This also explains points (ii) and (iii) above, that is, the fact that downstream mergers reduce upstream profits when $\mathrm{c}$ is high and also that the profitability of mergers increases with c.

Concerning point (iv), we show that when the alternative supply is inefficient enough (or in other words, when upstream market concentration is important) downstream mergers are pro-competitive, because the (large) reduction in the input price is passed on to consumers in the form of a lower final price. In other words, in the presence of strong market power upstream, downstream mergers countervail that market power, leading to a reduction in the final price. This result supports the view that "symmetry" between upstream and downstream markets increases welfare: a concentrated upstream sector must be compensated with a concentrated downstream market (Inderst and Shaffer (2008)). This has an important implication for competition policy: the competitive effect of a downstream merger depends on the market structure of the upstream 
sector.

Having argued about the key role of parameter c for our results, let us elaborate a bit more on the choice of an exogenous alternative supplier to model upstream competition. This is for the sake of tractability. It is well known that serious technical complications arise in situations where we have "interlocking" bilateral relations, in which rival upstream firms trade through non-linear contracts with the same competing downstream firms. As mentioned in a review article by Miklos-Thal et al. (2010, p.345) "The formal modeling of such "interlocking" vertical relations has proved difficult... and we still know relatively little about many basic questions... Interlocking relationships cause modeling issues such as either the inexistence or a large multiplicity of equilibria even in simple competition games." Also, Inderst (2010, p. 343) states that "... the benchmark model where competing upstream firms simultaneously make take-it-or-leave-it offers to competing downstream firms, may fail to have an equilibrium in pure strategies." There are, however, alternative modeling choices. For example, In Symeonidis (2010), downstream mergers are analyzed in a setting with two upstream and two downstream firms that bargain over a supply contract. In order to avoid the above mentioned technical difficulties, the author assumes that each downstream firm (or, in the case of a downstream merger, each division of the merged firm) and its upstream agent are locked into bilateral relations. This exclusivity assumption simplifies the analysis at the cost of not taking into consideration the possibility of an outside option for the downstream firms, which is key for our results. Symeonidis' paper focus on the relationship between the welfare effects of a downstream merger and the type of downstream competition, the type of bargaining and the type of supply contracts used in the vertical relationship. He does not analyze however, how the level of competition upstream affects the competitive impact of downstream mergers, which is the main focus of the present paper. To the best of our knowledge, this is the first paper to analyze 
downstream mergers in a setting with observable two-part tariff contracts and an alternative supply of the input. And it is precisely the combination of these two ingredients which allows us to get the interesting and unexpected result that a downstream merger can be welfare enhancing.

For example, with no alternative supply in our setting, it is well-known that the upstream monopolist could always monopolize the market by choosing the appropriate two-part tariff contracts. So, in that setting, downstream mergers would have no effect on final prices and social welfare. On the other hand, the most closely related paper to ours is Fauli-Oller and Bru (2008), who study the same model but in the context of secret two-part tariff supply contracts. They also obtain that profitability of a downstream merger increases with the inefficiency of the alternative supply. However, in their case, downstream mergers are always anticompetitive. The reason is that under secret contracts, a well known problem of opportunism arises that leads the upstream firm to set the wholesale price equal to the marginal cost of producing the input, regardless of the number of retailers. This implies that downstream mergers have no effect on the equilibrium wholesale price and then, their only effect is to reduce the level of competition. Finally, if we consider linear contracts, with or without an alternative supply, it can be shown (see for example Sandonís (2012)), that the wholesale prices are independent of the number of downstream firms so, in that context, downstream mergers would be anticompetitive also.

Summarizing, our framework proves to be a flexible setting that allows to capture the relationship between market structure (the number of downstream firms and the degree of competition upstream) and market outcomes (intermediate and final prices). We believe that this flexibility is particularly important for the analysis of issues that are relevant for competition policy.

There are several other theoretical papers in the literature that have dealt with downstream mergers. None of those papers, however, relate the competitive effects of downstream mergers 
with the level of competition upstream, which is the main goal of the present paper. For example, in the context of linear contracts and no alternative supply, von Ungern-Stenberg (1996), Dobson and Waterson (1997) and Chen (2003) show that downstream mergers can be welfare enhancing when there is strong enough competition downstream. Chipty and Snyder (1999) study the bargaining effects of downstream mergers in a setting with a monopoly upstream and non linear contracts, and relate the results with the curvature of the profit function of the supplier. Lommerurd et al. (2005, 2006) allow for a duopoly upstream but each downstream firm is assumed to be locked in a bilateral monopoly situation with its own independent input supplier, as in Symeonidis (2010), so that retailers have no outside options. They focus mainly on the profitability of downstream mergers in the first paper and on the comparison between national vs international mergers in the second one. Finally, Inderst and Wey (2003) analyze how downstream mergers affect upstream incentives to invest in cost reducing innovations in a model with bargaining and independent demands downstream.

The rest of the paper is organized as follows. In the next section, we analyze the optimal supply contracts taken market structure as given. In Section 3, we solve an example with an endogenous merger game in order to analyze the profitability of downstream mergers. Finally, Section 4 concludes. All proofs are relegated to the Appendix.

\section{The model}

We consider an upstream firm that produces an input at cost $c_{u}$. A number $n$ of downstream firms ${ }^{1}$ transform this input into a final homogenous good on a one-to-one basis, without addi-

\footnotetext{
${ }^{1}$ For analytical simplicity, we will ignore the integer constraint and will treat the number of firms (n) as a continuous variable on which everything depends differentiably according to the given relations, but we will restrict attention to integer realizations of this variable. This is a common practice in the Industrial Organization literature (see for example Salant et al (1983), Seade (1989), Bae and Choi (2007)) and many others.
} 
tional costs. Downstream firms may alternatively obtain the input from a competitive supply at cost $c<a$. Inverse demand for the final good is given by $P=a-Q$, where $Q$ is the total amount produced. ${ }^{2}$

The upstream firm sets observable vertical contracts that establish the terms under which inputs are transferred. After contracts are set, competition downstream is à la Cournot. More specifically, the game is modelled according to the following timing: first, the supplier offers a two-part tariff contract $(F, w)$ to downstream firms, where $F$ specifies a non-negative fixed amount and $w$ a wholesale price. Second, the downstream firms decide whether or not to accept the contract. The ones that accept, pay $F$ to the upstream firm. Finally, they compete à la Cournot, with the marginal costs inherited from the second stage. In particular, the firms that accept the contract have a marginal cost $w$ and the firms that do not accept the contract buy the input from the alternative supplier and have a marginal cost $c$.

Assume that $k$ firms have accepted a supply contract $(F, w)$. Firms that have not accepted the contract produce in equilibrium:

$$
q_{N}(k, w)= \begin{cases}\frac{a-c(k+1)+w k}{n+1} & \text { if } \quad w>\frac{-a+c(k+1)}{k} \\ 0 & \text { otherwise. }\end{cases}
$$

On the other hand, the firms that accept the contract produce in equilibrium:

$$
q(k, w)= \begin{cases}\frac{a+c(n-k)-w(n-k+1)}{n+1} & \text { if } \quad w>\frac{-a+c(k+1)}{k} \\ \frac{a-w}{k+1} & \text { otherwise. }\end{cases}
$$

Observe that, if $w$ is very low, the firms that do not accept the contract are driven out of the market. In that case, the firms that accept the contract produce the Cournot output when there are only $k$ active firms in the market. Profits of non-accepting and accepting firms are given,

\footnotetext{
${ }^{2}$ This would be equivalent to consider that the dominant input supplier is a final good manufacturer that distributes and sells the final good through a set of $n$ retailers.
} 
respectively, by $\Pi_{N}(k, w)=\left(q_{N}(k, w)\right)^{2}$ and $\Pi(k, w)=(q(k, w))^{2}$.

In the second stage, downstream firms accept the contract offered by the upstream firm whenever $F \leq \Pi(k, w)-\Pi_{N}(k-1, w)$. Obviously, as the upstream firm maximizes profits, in order for $k$ firms to accept the contract, ${ }^{3}$ it will choose $F$ to bind their participation constraint, that is, such that $F=\Pi(k, w)-\Pi_{N}(k-1, w)$. But this implies that the problem of choosing the optimal contract $(F, w)$ is equivalent to that of choosing $(k, w)$. Then, in the first stage, the upstream solves the following problem:

$$
\underset{k, w}{\operatorname{Max}} k\left(\Pi(k, w)-\Pi_{N}(k-1, w)+\left(w-c_{u}\right) q(k, w)\right)
$$

s.t. $1 \leq k \leq n$.

This problem has been already solved in the literature. Erutku and Richelle (2007) solve an equivalent problem for the case of a research laboratory licensing a cost-reducing innovation to a n-firms Cournot oligopoly through observable two-part tariff licensing contracts. Making use of this previously existing result we know that, regardless of the number of downstream firms, the upstream firm finds it profitable to sell the input to all of them ${ }^{4}$. Then, if we replace $\mathrm{k}$ by $\mathrm{n}$ and plug the corresponding profit expressions in the maximization problem of the upstream firm we get:

$$
\operatorname{Max}_{w}\left\{\begin{array}{l}
n \quad\left(\left(\frac{a-w}{n+1}\right)^{2}-\left(\frac{a-c n+w(n-1)}{n+1}\right)^{2}+\left(w-c_{u}\right)\left(\frac{a-w}{n+1}\right)\right) \\
\text { if } \quad c \geq w \geq \frac{-a+c n}{n-1} . \\
n \quad\left(\left(\frac{a-w}{n+1}\right)^{2}+\left(w-c_{u}\right)\left(\frac{a-w}{n+1}\right)\right) \\
\text { if } w<\frac{-a+c n}{n-1}
\end{array}\right.
$$

Direct resolution of this problem leads to the following result:

\footnotetext{
${ }^{3} \mathrm{As} \frac{\partial\left(\Pi(k, w)-\Pi_{N}(k-1, w)\right)}{\partial k}<0$, this is the only equilibrium in the acceptance stage.

${ }^{4}$ We prove this result in the appendix.
} 
Proposition 1 The optimal wholesale price is given by $w^{*}(n)=\frac{(n-1)\left(2 c n+c_{u}-a\right)+2 c_{u}}{2\left(1-n+n^{2}\right)}$ if $c<$ $\frac{a-c_{u}+\left(a+c_{u}\right) n^{2}}{2 n^{2}}$ and $w^{M}(n)=\frac{-a+c_{u}+\left(a+c_{u}\right) n}{2 n}$ otherwise. $^{5}$

The intuition for this result is as follows: concerning the optimality of selling to all firms, we know that with a fixed fee contract, the input would be sold to only a subset of firms in order to protect industry profits from competition (Kamien and Tauman (1986)). With a two-part tariff contract however, the upstream firm can always sell the input to more firms without affecting the level of competition, by choosing an appropriate (higher) wholesale price. In other words, the upstream firm may always use the wholesale price to control for the level of competition. ${ }^{6}$

Concerning the equilibrium contract, the optimal wholesale price trade-offs two conflicting incentives. On the one hand, maximizing industry profits requires a high wholesale price; on the other hand, reducing the outside option of downstream firms asks for a low wholesale price. Observe that whenever $c \geq \frac{a-c_{u}+\left(a+c_{u}\right) n^{2}}{2 n^{2}}$, the alternative supply becomes zero and the upstream firm obtains the full monopoly profits.

An important result in this paper is the sign of relationship between $w^{*}$ and $n$, that is, how a downstream merger affects the equilibrium wholesale price charged by the dominant upstream firm, which is given by the following proposition:

Proposition 2 The optimal wholesale price $w^{*}$ is an increasing function of $n\left(\frac{d w^{*}(n)}{d n}>0\right)$, it

\footnotetext{
${ }^{5}$ Notice that we are not restricting the wholesale price to be lower than $\mathrm{c}$, the cost of the alternative supplier. In principle, a possibility could be for the dominant upstream firm to set a wholesale price higher than c, and then compensate the retailers with a negative fixed fee. However, this is never optimal because, as Proposition 2 below shows, the optimal wholesale price is always lower than c.

${ }^{6}$ This argument is also used in Sen and Tauman (2007) to prove that with an auction plus royalty contract, a cost reducing innovation would be sold to all firms by an outsider patentee, and also by Faulí-Oller, González and Sandonís (2012) to show that the same result holds for the case of differentiated goods and for both an outsider and an insider patentee.
} 
is lower than $c$, and tends to $c$ as $n$ tends to infinity. ${ }^{7}$

In other words, a downstream merger, by reducing the number of downstream firms, leads to a drop in the optimal wholesale price charged by the upstream firm. This is a necessary condition in order for a downstream merger to be able to increase welfare. The intuition behind this result is as follows: a downstream merger, by reducing the level of competition in the downstream market, helps to increase total industry profits; on the other hand, the incentive to reduce the outside option of downstream firms becomes more binding because a merger increases these outside options. Therefore, a downstream merger leads the upstream firm to put more weight on the second incentive, reducing the wholesale price in order to reduce the outside option of downstream firms.

It is key also to emphasize the key role played by parameter $c$. It affects the way in which the upstream firm adjusts the wholesale price as $n$ changes. This is formalized by the following proposition:

Proposition 3 As the alternative supplier becomes more inefficient, the upstream firm adjusts the wholesale price faster as $n$ changes; formally:

$$
\frac{\partial^{2} w^{*}(n)}{\partial n \partial c}=\frac{2 n-1}{(1+n(n-1))^{2}}>0
$$

A higher value of $c$ reduces the outside option of downstream firms for a given $n$. This implies that a downstream merger produces a proportionally larger increase of the outside option, that must be compensated by the upstream firm with a larger reduction of the wholesale price. In other words, the countervailing effect of a horizontal merger is larger when the alternative supply is more inefficient. This is very important because only when the wholesale price adjusts sufficiently fast to changes in $n$, it may be the case that a reduction in $n$ leads to a reduction in

\footnotetext{
${ }^{7}$ This result holds for any $n \geq 2$. Observe that, if $c<\frac{a+3 c_{u}}{4}, w^{*}(1)=c_{u}>w^{*}(2)$.
} 
the final price paid by consumers. And this happens for high values of $c$. In other words, when we have a sufficiently concentrated upstream sector, the optimal merger policy should prescribe a lenient merger policy in the downstream level in order to balance the situation. This result supports the view that "symmetry" between the upstream and downstream markets increases social welfare (Inderst and Shaffer, (2008)).

The next step in the analysis is then to predict under what circunstances the lower wholesale price obtained by downstream firms after a horizontal merger will be passed on to consumers. So first, we have to compute the equilibrium final price.

$>$ From the previous results, it is direct to compute that price, which is given by:

$$
P^{*}(n)=\left\{\begin{array}{cc}
\frac{2 c(n-1) n^{2}+a(2+n(n-1))+c_{u} n(n+1)}{2\left(1+n^{3}\right)} & \text { if } c \leq \frac{a+c_{u}}{2} \text { or } c>\frac{a+c_{u}}{2} \text { and } n<\sqrt{\frac{a-c_{u}}{2 c-a-c_{u}}} . \\
\frac{a+c_{u}}{2} & \text { otherwise }
\end{array}\right.
$$

Next, we have to analyze the evolution of the equilibrium price with respect to $n$. For large values of $c$, the upstream firm gets the full monopoly profits and then the final price does not depend on $n$. Otherwise, it is useful to write the final price as a function of the input price, namely, $P^{*}\left(w^{*}(n)\right)=\frac{a+n w^{*}(n)}{n+1}$. Then we have:

$$
\frac{\partial P^{*}\left(w^{*}(n)\right)}{\partial n}=\frac{n(n+1) \frac{\partial w^{*}(n)}{\partial n}-\left(a+n w^{*}\right)}{(n+1)^{2}}
$$

As we can see in expression (3), the effect of a downstream merger on the final price crucially depends on the effect that the merger has on the equilibrium wholesale price. In particular, only when a horizontal merger leads to a large reduction in the wholesale price we may have that $\frac{\partial P^{*}}{\partial n}>0$. It is direct to compute that this is the case whenever $c>c^{\prime}(n)$, where $c^{\prime}(n)$ $=\frac{c_{u}(n-1)(n+1)^{3}+a\left(1-2 n+6 n^{2}-2 n^{3}+n^{4}\right)}{2 n\left(-2+3 n+n^{3}\right)}$ and $c^{\prime}(n)<\frac{a+c_{u}}{2}$. Therefore, downstream mergers lead to a decrease of the final price whenever the level of competition upstream is sufficiently low ( $c$ is high enough). Notice that this only applies to the case $n \geq 2$ because we have that 
$P^{*}(1)>P^{*}(2)$ regardless of $c$, that is, a downstream merger to monopoly is anticompetitive in our setting regardless of the level of competition upstream. This would provide a theoretical justification for the view expressed in the recent U.S. Merger Guidelines (2010) according to which "efficiencies almost never justify a merger to monopoly or near-monopoly". Observe also that, in this model, given that all downstream firms buy the input from the efficient supplier in equilibrium, social welfare (and consumer surplus) is a decreasing function of price. Then, we have that the welfare effect of a downstream merger depends on its effect on the equilibrium final price. This effect depends on $c$, that parametrizes the level of competition upstream, and $n$, the number of downstream firms. We summarize the previous result in the following proposition, which is the central result in the paper:

Proposition 4 If $n \geq 2$, downstream mergers increase social welfare whenever $c>c^{\prime}(n)$, where $c^{\prime}(n)=\frac{c_{u}(n-1)(n+1)^{3}+a\left(1-2 n+6 n^{2}-2 n^{3}+n^{4}\right)}{2 n\left(-2+3 n+n^{3}\right)}$.

For illustrative purposes, Figure 1 plots $c^{\prime}(n)$ for the particular case $c_{u}=0$.

As we can see in Figure 1, first, for large enough values of $c$, the upstream firm monopolizes the market. In this region, downstream mergers do not affect the final price. Second, below the monopoly region but above $c^{\prime}(n)$, the derivative of the final price with respect to $n$ is positive. This implies that horizontal mergers downstream countervail the dominant position of the upstream firm, leading to a final price reduction. Third, below $c^{\prime}(n)$, there is little market power upstream and then, downstream mergers have the main effect of reducing competition, leading to a price increase.

We can observe also in Figure 1 that, for a given value of c (above 0.36a), downstream mergers are welfare improving only for sufficiently low values of $n$, that is, whenever the level of competition downstream was already low before the merger. The intuition could be the following: if there are many downstream firms, a two-firms merge for example, would change 


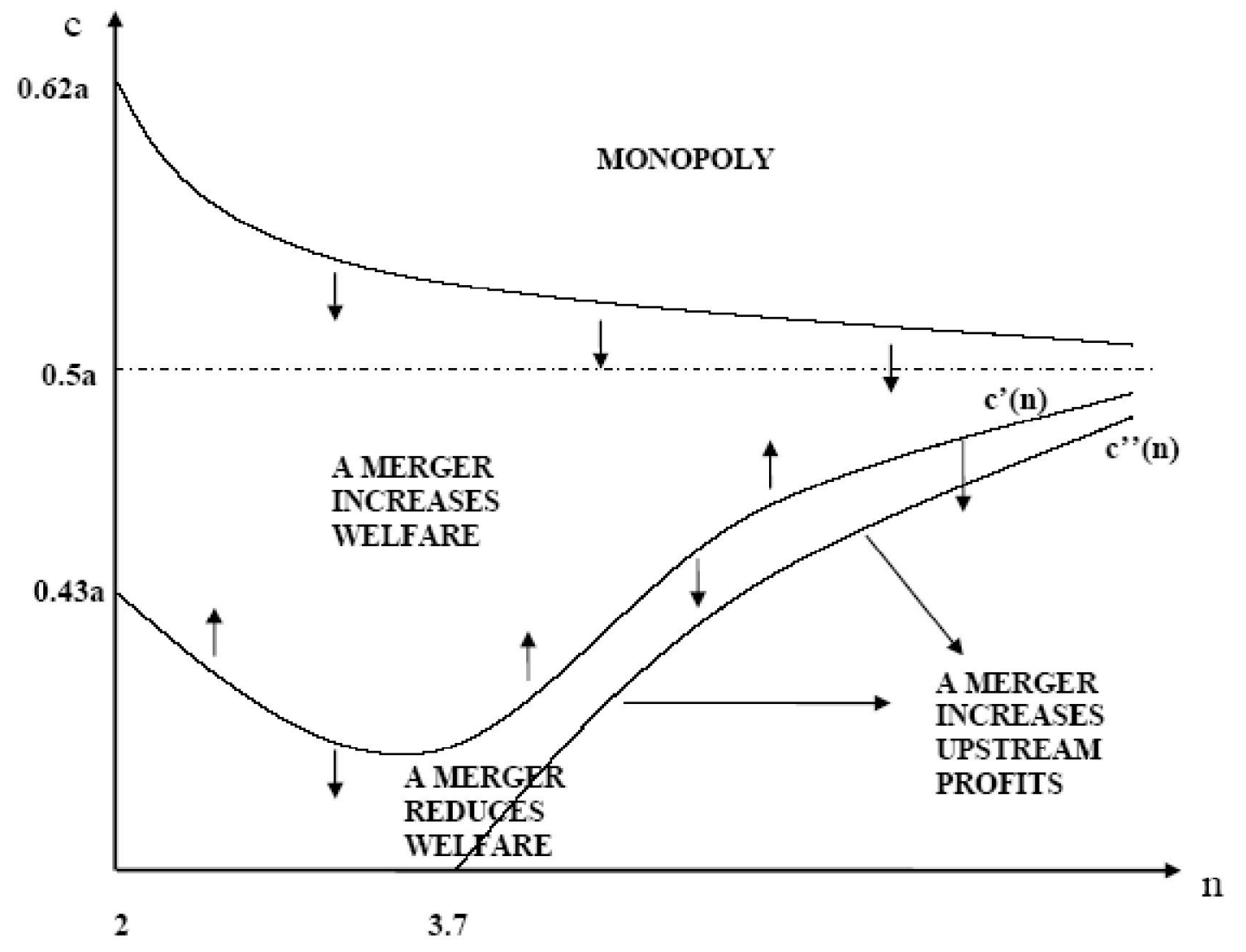

Figure 1: Welfare effects of downstream mergers 
both competition and the outside option of downstream firms very little. When there are fewer firms however, a two-firm merge increases significantly both market profits and outside options (imagine for example, going from 3 to 2 firms). Then, when the level of competition downstream is already low, any downstream merger forces the upstream firm to put more weight on the reduction of the outside options, reducing more the wholesale price, and, as a result, leading to a reduction in the final price paid by consumers.

A direct implication in terms of merger policy is that we should prescribe a lenient merger policy in the downstream market when there is a high level of market concentration in the upstream sector. In this case, downstream mergers should be allowed in order to countervail the strong market power upstream. This supports the view that "symmetry" between the downstream and upstream sectors is good for welfare (Inderst and Shaffer (2008).

We next compute the equilibrium profits of upstream and downstream firms. They are given, respectively, by:

$$
\begin{gathered}
\Pi^{U}(n)=\left\{\begin{array}{cc}
\frac{n\left(\left(a-c_{u}\right)\left(\left(a-c_{u}\right)\left(1+n^{2}\right)-2\left(a-2 c+c_{u}\right)\right)+4(a-c)\left(c-c_{u}\right) n^{3}\right)}{4\left(1+n+n^{3}+n^{4}\right)} & \text { if } c \leq \frac{a+c_{u}}{2} \text { or } c>\frac{a+c_{u}}{2} \text { and } n<\sqrt{\frac{a-c_{u}}{2 c-a-c_{u}}} \\
\left(\frac{a-c_{u}}{2}\right)^{2} & \text { otherwise. }
\end{array}\right. \\
\Pi^{D}(n)=\left\{\begin{array}{cc}
\left(\frac{a-c_{u}+\left(a-2 c+c_{u}\right) n^{2}}{2\left(n^{3}+1\right)}\right)^{2} & \text { if } c \leq \frac{a+c_{u}}{2} \text { or } c>\frac{a+c_{u}}{2} \text { and } n<\sqrt{\frac{a-c_{u}}{2 c-a-c_{u}}} \\
0 & \text { otherwise. }
\end{array}\right.
\end{gathered}
$$

Concerning the upstream profits, they are increasing (decreasing) in $n$ for $c>(<) c^{\prime \prime}(n)$, where $c^{\prime \prime}(n)=\frac{c_{u}(1+n)^{3}+a(n-1)(1+(-4+n) n)}{2 n(4+(n-1) n)}$, and $c^{\prime \prime}(n)<c^{\prime}(n)<\frac{a+c_{u}}{2}$. Combining this result with the one on welfare, it is easy to see that any merger that increases the upstream profits reduces social welfare (see Figure 1, where we have also plotted $c^{\prime \prime}(n)$ ). This result is intuitive because horizontal mergers increase welfare only when they countervail the buyer power of the dominant upstream firm. Observe that we find that more competition downstream may be good for the upstream firm. This is due to the negative effect that the level of competition 
downstream has on the outside option of downstream firms. ${ }^{8}$

Concerning joint downstream profits, we have that they are decreasing in $n$. In other words, downstream mergers increase joint downstream profits. However, this result does not necessarily imply that there will be private incentives to merge, due to the positive externality that the merger imposes on outsiders. This is what we analyze in the next section, designing an endogenous merger formation game. But before, let us just emphasize how merger profitability depends on $c$. A merger of $k+1$ firms is profitable if

$$
\Pi^{D}(n-k)-(k+1) \Pi^{D}(n) \geq 0 .
$$

This condition holds if $c \geq \frac{a-c_{u}+\left(a+c_{u}\right) n^{2}}{2 n^{2}}$ because, in this case, $\Pi^{D}(n)=0$. Otherwise, it is useful to study profitability rewriting (5) in the following way:

$$
\frac{\Pi^{D}(n-k)}{\Pi^{D}(n)} \geq(k+1)
$$

It is direct to see that the left hand side of the inequality is increasing in $c$. This means that mergers become more likely as $c$ increases, that is, as the market power of the dominant upstream firm increases. Bru and Fauli-Oller (2008) obtain the same result but considering secret supply contracts. Let us now introduce an illustrative example of a merger formation game.

\section{An endogenous merger game}

One of the most widely accepted merger games is the one developed by Kamien and Zang (1990). In this paper, each firm simultaneously chooses a bid for each competitor and an asking price. A firm is sold to the highest bidder whose bid exceeds the firm's asking price. They get that, with linear demand and Cournot competition, monopolization does not occur when we have three or

\footnotetext{
${ }^{8}$ Caprice (2005) obtains the same result for the case of secret contracts.
} 
more firms. Buying firms is expensive because, by not accepting a bid, a firm free-rides on the reduction in competition induced by the remaining acquisitions.

In this section, we propose an example of a merger game, inspired in the previous paper, in order to endogenize the market structure. We want to analyze how profitable downstream mergers are in the presence of endogenous input prices. For simplicity, we restrict attention to a simple game where there is only one acquiring firm. ${ }^{9}$

The timing of the game is the following: we assume that there are, initially, $N$ symmetric downstream firms in the industry. One of them, say firm 1, can make simultaneous bids to acquire rival firms.

In the first stage, firm 1 offers bids $b_{i}$ to buy firm $\mathrm{i}(i=2, . . n)$. In the second stage, these firms decide simultaneously whether to accept the bid or not. If firm $i$ accepts the offer, it sells the firm to firm 1 at the price $b_{i}$. Given the equilibrium market structure that results at the end of stage two, the contract game of the previous section is played.

Given that solving this game for any possible value of parameter $\mathrm{c}$ is unfeasible, let us fix two values for parameter $c$ and assume $c_{u}=0$. Given that we know that merger profitability increases with $c$, we are going to solve the game for a high value of c $\left(c=\frac{a}{2}\right)$ and for a low value of c $\left(c=\frac{a}{10}\right)$. In the latter case, downstream mergers always lead to an increase in the final price. In the former case, they always reduce the final price up to duopoly (in a monopoly the price takes its highest value). We expect more mergers to take place when parameter $c$ is high. As we will see below, this is exactly what happens.

\footnotetext{
${ }^{9}$ In Kamien and Zang (1990) there is multiplicity of equilibria. In particular, no merger is always an equilibrium. When we obtain that monopolization is an equilibrium in our model, it would also be an equlibrium in Kamien and Zang's model. In this equilibrium, we would have one firm asking infinity and bidding the duopoly profits for the other firms, and the remaining firms asking for the duopoly profits to sell their firms and bidding zero for the other firms.
} 
We solve by backward induction starting at stage two. Suppose that at the end of stage 2 , there are $n$ independent downstream firms. They would obtain the following profits in the market stage:

$$
\Pi^{D}(n)=\frac{a^{2}}{4\left(1+n^{3}\right)^{2}} \text { if } c=\frac{a}{2} \text { and } \Pi^{D}(n)=\left(\frac{5 a+4 a n^{2}}{10\left(1+n^{3}\right)}\right)^{2} \text { if } c=\frac{a}{10} .
$$

This expressions are obtained just by plugging $c=\frac{a}{2}$ or $c=\frac{a}{10}$ into expression (4). ${ }^{10}$

Firms will accept the offers of firm 1 whenever the bid is not lower than their outside option, which of course depends on the acceptance decisions of the other firms. If, for example, $k-1$ firms (other than firm $\mathrm{j}$ ) accepted, the outside option of firm $\mathrm{j}$ would be $\Pi^{D}(N-k+1$ ). At the first stage, firm 1 has to decide the number of firms to acquire, taking into account that in order to buy $k$ firms it has to make a bid of $\Pi^{D}(N-k+1)$. Then, the payoff of firm 1 as a function of the number of acquisitions $k$ is given by:

$$
\Pi^{D}(N-k)-k \Pi^{D}(N-k+1)
$$

The maximizer of the previous expression is summarized in the following proposition:

Proposition 5 (a) If $c=\frac{a}{2}$, then, if $N \leq 21$, monopolization takes place. Otherwise, no merger occurs.

(b) If $c=\frac{a}{10}$, then, if $N \leq 4$, monopolization takes place. Otherwise, no merger occurs.

\section{Proof. See Appendix}

Proposition 5 shows that monopolization is the equilibrium outcome even for very unconcentrated industries whenever there is strong market power upstream ( $c$ is high). When the

\footnotetext{
${ }^{10}$ By looking at the above expressions, it is easy to see that downstream mergers are very profitable in this setting. For example, the monopoly profits would be almost 21 times the duopoly profits in the case where $c=a / 2$ and almost 4 times the duopoly profits when $c=a / 10$, whereas in a standard Cournot model, they would be only 2.25 times the duopoly profits.
} 
upstream sector is more competitive, however, merger to monopoly occurs in equilibrium only in concentrated markets. Our results contrasts with the lack of profitability of horizontal mergers found in Kamien and Zang (1990), where, in a standard Cournot setting, monopolization occurs in equilibrium only if the pre-merger market structure is a duopoly.

A natural question to address at this point is how competition authorities should perform in this market. If $c$ is low, we know that downstream mergers increase the final price and they should be forbidden. Instead, when $c$ is high, downstream mergers up to duopoly reduce the final price. Therefore, in the latter case, the optimal merger policy should allow all mergers except the one leading to monopolization. Similar calculations as in Proposition 5 show that, under the optimal merger policy, mergers up to duopoly would take place in equilibrium whenever $N<13$.

Finally, observe that from Proposition 5, it is easy to check that whenever $4<n \leq 21$, an increase in the value of parameter $c$ from $a / 10$ to $a / 2$ would trigger a monopolization of the downstream sector. Suppose, for example, that we have 3 firms in the upstream sector: firm U and two competitive firms (A and B) that produce the input respectively with marginal costs $\mathrm{a} / 10$ and $\mathrm{a} / 2$. In this setting, a merger between firms $\mathrm{U}$ and $\mathrm{A}$ would increase parameter $\mathrm{c}$ from $\mathrm{a} / 10$ to $\mathrm{a} / 2$ and would therefore trigger a takeover wave in the downstream sector, whenever $4<n \leq 21$. This observation could help to explain the parallel processes of consolidation of upstream and downstream sectors observed in several industries (see for example, Sexton (2000) for the food market, or Lockshin (2002) for the wine market).

\section{Conclusions}

In this paper we analyze the formal relationship between the competitive effects of horizontal mergers downstream and the level of market competition upstream. With this aim, we have considered a model with a dominant upstream firm selling an input to a set of $\mathrm{n}$ downstream firms 
through observable two-part tariff contracts and with the presence of a less efficient, alternative supply to whom the downstream firms can buy the input if they do not reach an agreement with the dominant supplier. This setting proves to be very useful to analyze the interaction between the market structure and the market outcomes. We show that downstream mergers induce the upstream firm to offer lower wholesale prices with the aim to reduce the outside option of downstream firms. This reduction offsets the anticompetitive effect of a merger whenever the alternative supplier is sufficiently inefficient, that is, when there is strong market power upstream. In this case, downstream mergers countervail the market power of the dominant supplier, leading to an increase in consumer surplus and social welfare.

Concerning profitability, we find that it increases with the (cost) inefficiency of the alternative supply. Indeed, in an endogenous merger formation game we obtain that, in contrast to what happens when input prices are exogenous, monopolization occurs even for very unconcentrated industries, whenever there is high market concentration upstream. In that case, our results would call for a lenient merger policy towards downstream mergers.

For tractability, our analysis leaves out some features of real markets. For example, we have focused on the case of symmetric downstream firms and non-discriminatory two-part tariff contracts. The effect of price discrimination among downstream firms that differ either in marginal costs or in the quality of their goods has been analyzed in Inderst and Shaffer (2009), in a setting with observable two-part tariff contracts. They get that the differences among downstream firms are amplified through the optimal contracts because more efficient firms are offered lower wholesale prices than less efficient ones, which increases allocative efficiency. They also find that forbidding price discrimination may lead to an increase of all wholesale prices, leading to a reduction in consumer surplus and social welfare.

Even though we have used specific functional forms in the paper in order to be able to obtain 
explicit results, some of the mechanisms that underlie the results are more general. For example, in the appendix we show that the result that the input is sold to all firms in the downstream industry under observable two-part tariff contracts holds for a more general class of demands. Also, the result that the equilibrium wholesale price decreases after a downstream merger, is not specific to the linear demand assumption. The intuition is that this result depends on the trade off between maximizing industry profits and minimizing the outside option of downstream firms that the upstream firm faces. A downstream merger, by reducing competition downstream should help the first incentive and hurt the second one independently of the demand function. And it is the combination of these two effects what gives the upstream firm more flexibility to reduce the wholesale price in order to help the second incentive. And, finally, the existence of a trade-off between a lower input price and less competition downstream after a merger, that determines the welfare effect of a merger, must be quite general also.

To conclude, we want to discuss a possible alternative interpretation of parameter $c$, the cost of the alternative supply. As we have discussed above, this parameter can be interpreted as a measure of the degree of competition upstream. The larger $c$ the higher the monopolistic power of the dominant upstream firm. Then, it would be interesting to study settings where the parameter $c$ is endogenously determined. One possible application would be to consider that the alternative supply is an international market for the input and the upstream supplier is a national firm. In this setting, it would be of interest the analysis of the optimal tariff. The effect of this trade policy on social welfare is not straightforward though. On the one hand, a tariff would increase the wholesale price and the final price for a given number of firms, which hurts consumers and welfare. On the other hand, the imposition of a tariff would increase the monopolistic power of the upstream firm, which induces more mergers downstream. But in our model, downstream mergers may be welfare enhancing. The final effect of a tariff would depend 
on the balance of these two effects. This and some other possible applications of our model are left for future research.

\section{Appendix}

Proof of the upstream firm incentives to sell the input to all downstream firms

We have that

$$
\begin{aligned}
\pi(k, w)= & \left(P-c_{u}\right)\left((n-k) q_{N}(k, w)+k q(k, w)\right)-k\left(q_{N}(k-1, w)\right)^{2}-(n-k)\left(q_{N}(k, w)\right)^{2}- \\
& -\left(c-c_{u}\right)(n-k) q_{N}(k, w) .
\end{aligned}
$$

Observe that if the upstream sells to $n$ firms with the wholesale price $w_{1}$, the first term in the above expression will also appear in $\pi\left(n, w_{1}\right)$. Then the difference in profits is given by:

$$
\begin{aligned}
\pi\left(n, w_{1}\right)-\pi(k, w)= & k\left(q_{N}(k-1, w)\right)^{2}+(n-k)\left(q_{N}(k, w)\right)^{2}+ \\
& +\left(c-c_{u}\right)(n-k) q_{N}(k, w)-n\left(q_{N}\left(n-1, w_{1}\right)\right)^{2} .
\end{aligned}
$$

In order to prove the lemma we have to check that the previous expression is non-negative in the following three different regions:

when $c \geq w>c+\frac{-a+c}{k}$, where $q_{N}(k, w)>0$ and $q_{N}(k-1, w)>0$,

when $\frac{-a+c k}{-1+k}<w \leq c+\frac{-a+c}{k}$, where $q_{N}(k, w)=0$ and $q_{N}(k-1, w)>0$ and

when $w \leq \frac{-a+c k}{-1+k}$, where $q_{N}(k, w)=0$ and $q_{N}(k-1, w)=0$.

If $c \geq w>c+\frac{-a+c}{k}$, we have that $w \leq w_{1}=\frac{c(n-k)+k w}{n} \leq c$ and

$$
\begin{aligned}
\pi\left(n, w_{1}\right)-\pi(k, w) & >k\left(q_{N}(k-1, w)\right)^{2}+(n-k)\left(q_{N}(k, w)\right)^{2}-n\left(q_{N}\left(n-1, w_{1}\right)\right)^{2}= \\
& =\frac{(n-k) k(c-w)^{2}}{n(1+n)} \geq 0 .
\end{aligned}
$$

If $\frac{-a+c k}{-1+k}<w \leq c+\frac{-a+c}{k}$, we have that $w<w_{1}=\frac{a(n-k)+k(n+1) w}{(k+1) n}<c$ and $q_{N}(k, w)=0$. 
We have to distinguish two cases:

If $\frac{c(1+k) n^{2}-a\left(k+n^{2}\right)}{k\left(n^{2}-1\right)}<w \leq c+\frac{-a+c}{k}$, we have that $q_{N}\left(n-1, w_{1}\right)>0$. To sign the difference in profits we obtain that

$$
k q_{N}(k-1, w)-n q_{N}\left(n-1, w_{1}\right) \geq 0 .
$$

This implies that

$$
\pi\left(n, w_{1}\right)-\pi(k, w)=k\left(q_{N}(k-1, w)\right)^{2}-n\left(q_{N}\left(n-1, w_{1}\right)\right)^{2}>0
$$

If $\frac{-a+c k}{-1+k}<w \leq \frac{c(1+k) n^{2}-a\left(k^{c}+n^{2}\right)}{k\left(n^{2}-1\right)}$, then $w_{1} \leq \frac{-a+c n}{-1+n}$ and, therefore, $q_{N}\left(n-1, w_{1}\right)=0$. Then,

$$
\pi\left(n, w_{1}\right)-\pi(k, w)=k\left(q_{N}(k-1, w)\right)^{2}>0 .
$$

If $w \leq \frac{-a+c k}{-1+k}$, we have that $w_{1}=\frac{a(n-k)+k(n+1) w}{(k+1) n} \leq \frac{-a+c n}{-1+n}$ and, therefore, $q_{N}\left(n-1, w_{1}\right)=0$. As we have also that $q_{N}(k-1, w)=0$, then

$$
\pi\left(n, w_{1}\right)-\pi(k, w)=0 .
$$

We can show that this result also holds for concave demands satisfying a technical restriction concerning the third derivative of the inverse demand. We can also show that it holds for the class of demands $P=A-X^{b}$, where $b \geq 1$.

\section{Proof of Proposition 5}

The objective of firm 1 is given by expression (6):

$$
F(N, k)=\Pi^{D}(N-k)-k \Pi^{D}(N-k+1)
$$

Consider the case $c=a / 2$. Simple computations show that whenever $N<25$, the result in the text holds. For $N \geq 25$, we proceed as follows. We check that for $m \geq 9$

$$
\frac{\Pi^{D}(m)}{\Pi^{D}(m+1)}<2
$$


This implies that for $N-9 \geq k \geq 2$, we have that $\frac{\Pi^{D}(N-k)}{\Pi^{D}(N-k+1)}<2$. This implies that $F(N, k)<0$. For $N-1 \geq k \geq N-8$, simple computations show that $F(N, k)<0$. Finally, $k=1$ yields less profits that $k=0$, because of (8). A similar analysis yields the second part of the proposition, that is, the case $c=a / 10$.

\section{References}

Bae, S. and Choi, J., 2007, "The Optimal number of firms with an application to professional sports leagues", The Journal of Sports Economics 8 (1), 99-108.

Bru, L. and R. Faulí-Oller,., 2008, "Horizontal Mergers for Buyer Power", Economics Bulletin $12(3)$, pp. 1-7.

Bhattacharyya, S. and A. Nain, 2011, "Horizontal acquisitions and buying power: A product market analysis", Journal of Financial Economics 99 (1), 97-115.

Caprice, S., 2005, "Incentive to encourage downstream competition under bilateral oligopoly", Economics Bulletin, 12. 9. pp.1-5.

Chipty, T. and C. Snyder, 1999, "The Role of Buyer Size in Bilateral Bargaining: A Study of the Cable Television Industry", Review of Economics and Statistics, 81(2), 326-340.

Dobson, P.W and M. Waterson, 1997, "Countervailing Power and Consumer Prices", The Economic Journal 107, 418-30.

Erutku, C. and Y. Richelle, 2007, "Optimal licensing contrcat and the value of a patent", Journal of Economics and Management Strategy, 16(2), 407-436.

Fauli-Oller, R. and L. Bru, 2008, "Horizontal Mergers for Buyer Power", Economics Bulletin $12,1-7$

Faulí-Oller, R., González X. and J. Sandonís, 2012, "Optimal two part tariff licensing contracts with differentiated goods and endogenous R\&D", The Manchester School, 81(5), 803-827. 
Fee, C. and S. Thomas, 2004. "Sources of gains in horizontal takeovers: evidence from customer, supplier and rival firms". Journal of Financial Economics 74, 423-460.

Inderst, R., 2010, "Models of Vertical Market Relations", International Journal of Industrial Organization 28 (4), 341-344.

Inderst, R. ans G. Shaffer, 2008, "Buyer power in merger control", chapter XX in ABA Antitrust Section Handbook, Issues in Competition, Law and Policy, W. D. Collins, ed.

Inderst, R. and G. Shaffer, 2009, "Market power, price discrimination and allocative efficiency in intermediate-goods markets", Rand Journal of Economics 40 (4), 658-672.

Inderst, R. and C. Wey, 2003, "Bargaining, mergers and technology choice", RAND Journal of Economics, 34 (1), 1-19

Kamien, M. and Y. Tauman,1986, "Fees versus royalties and the private value of a patent", The Quarterly Journal of Economics 101, 471-491.

Kamien, M. and I. Zang,1990, "The limits of monopolization through acquisition", The Quarterly Journal of Economics, 105, 465-499.

Kamien, M. and I. Zang, 1991, "Competitively cost advantageous mergers and monopolization", Games and Economic Behavior, 3, 323-338.

Kamien, M. and I. Zang,1993, "Monopolization by sequential acquistion", The Journal of Law, Economics and Organization 9(2), 205-229.

Lockshin, L., 2002, "Globalization and wine branding", Economies et Societés, 25, 1573-1590.

Lommerud, K., Straume, O. and L. Sorgard, 2005, "Downstream merger with upstream market power", European Economic Review 49, 717-743.

Lommerud, K., O. Straume and L. Sorgard, 2006, "National versus international mergers in unionized oligopoly", RAND Journal of Economics 37(1), 212-233.

Miklós-Thal, J., Rey, P. and Vergé, T., 2010. "Vertical relations", International Journal of 
Industrial Organization 28, 345-349.

Seade, J., 1980, "On the effects of entry", Econometrica 48 (2), 479-489.

Salant, S., Switzer, S. and Reynolds R., 1983, "The effects of an exogenous change in industry structure on Cournot-Nash equilibrium", The Quarterly Journal of Economics 98 (2), 185-199.

Sen, D. and Tauman, Y., 2007, "General licensing schemes for a cost-reducing innovation", Games and Economic Behavior, 59,1, 163-186.

Sexton, R.J., 2000, "Industrialization and consolidation in the US food sector. Implications for competition and welfare", American Journal of Agricultural Economics, 82, 1087-1104.

Symeonidis, G., 2010, "Downstream Merger and Welfare in a Bilateral Oligopoly", International Journal of Industrial Organization, 28, 230-243.

Von Ungern-Sternberg, T.,1996, "Countervailing Power Revisited", International Journal of Industrial Organization 14, 507-520. 